ISSN 0103-9954

\title{
EMERGÊNCIA E ESTABELECIMENTO DE PLÂNTULAS DE Guazuma ulmifolia LAM. EM FUNÇÃO DE DIFERENTES TRATAMENTOS PRÉ-GERMINATIVOS
}

\author{
SEEDLING EMERGENCE AND ESTABLISHMENT OF Guazuma ulmifolia LAM. SUBMITTED TO \\ DIFFERENT PRE-GERMINATION TREATMENTS
}

\author{
Diellen Librelon da Silva ${ }^{1}$ Giovana Rodrigues da Luz ${ }^{2}$ Maria das Dores Magalhães Veloso \\ Geraldo Wilson Fernandes ${ }^{4}$ Yule Roberta Ferreira Nunes ${ }^{5}$
}

\begin{abstract}
RESUMO
Este trabalho testou a influência de métodos de escarificação térmica e mecânica na emergência e estabelecimento de plântulas de Guazuma ulmifolia. As sementes foram submetidas aos tratamentos pré-germinativos de (1) escarificação mecânica (lixa), e (2) escarificação térmica (água quente), além do tratamento-controle (3) no qual as sementes foram deixadas intactas. O tratamento feito com escarificação térmica diferiu dos demais tratamentos, apresentando o maior número de plântulas emergidas. As sementes tratadas com lixa obtiveram a menor porcentagem de emergência, não diferindo do tratamento-controle. Para o índice de velocidade de germinação não foi verificada diferença significativa entre os tratamentos e o pico de emergência de plântulas foi entre o $13^{\circ}$ e $15^{\circ}$ dia de incubação em todos os tratamentos. Quanto ao estabelecimento, o crescimento (altura, diâmetro e número de folhas e de nós) das plântulas diferiu entre os tratamentos pré-germinativos. Observou-se maior crescimento das plântulas após suas sementes passarem por escarificação térmica. Assim, a escarificação com água quente é o método mais adequado para quebra da dormência das sementes de Guazuma ulmifolia, proporcionando plântulas mais vigorosas.
\end{abstract}

Palavras-chave: dormência; comportamento germinativo; estabelecimento.

\section{ABSTRACT}

This study tested the influence of mechanical and thermal scarification methods on emergence and establishment of Guazuma ulmifolia seedlings. Seeds were subjected to pre-germination treatments of (1) mechanical scarification (sandpaper), and (2) thermal scarification (hot water), in addition to the control treatment (3) from which the seeds were left intact. The thermal scarification treatment differed from the other treatments featuring the largest number of seedling emergence $(70 \%)$. The seeds treated with sandpaper achieved the lowest emergence percentage not differing from the control treatment. For the germination speed index no significant difference between treatments has been verified and the emergence peak was between the $13^{\text {rd }}$ and $15^{\text {th }}$ days of incubation in all treatments. In the establishment, the seedlings growth (height, diameter and number of leaves and nodes) presented differences between the treatments. It

1 Bióloga, Msc., Laboratório de Ecologia Vegetal, Departamento de Biologia Geral, Universidade Estadual de Montes Claros, Campus Universitário Prof. Darcy Ribeiro, CP 126, CEP 39401-089, Montes Claros (MG), Brasil. diellenbio@hotmail.com

2 Bióloga, Msc., Doutoranda do Programa de Pós-Graduação em Ecologia, Conservação e Manejo da Vida Silvestre, Universidade Federal de Minas Gerais, CEP 31270-901, Belo Horizonte (MG), Brasil. giovanaluz@gmail.com

3 Bióloga, Dra ${ }^{a}$, Professora Efetiva, Laboratório de Ecologia e Propagação Vegetal, Universidade Estadual de Montes Claros, Campus Universitário Prof. Darcy Ribeiro, CP 126, CEP 39401-089, Montes Claros (MG), Brasil. doraveloso13@gmail.com

4 Biólogo, Dr., Professor Titular, Laboratório de Ecologia Evolutiva \& Biodiversidade, Departamento de Biologia Geral, Universidade Federal de Minas Gerais, Caixa Postal 486, CEP 31270-901, Belo Horizonte (MG), Brasil. gw.fernandes@gmail.com

5 Bióloga, Dr ${ }^{\mathrm{a}}$., Professora Efetiva, Laboratório de Ecologia Vegetal, Departamento de Biologia Geral, Universidade Estadual de Montes Claros, Campus Universitário Prof. Darcy Ribeiro, Caixa Postal 126, CEP 39401-089, Montes Claros (MG), Brasil. yule.rfnunes@gmail.com

Recebido para publicação em 13/11/2012 e aceito em 23/10/2014 
was observed further development of seedlings after their seeds go through thermal scarification. Therefore, scarification with hot water is the most appropriate method for breaking the dormancy of seeds of Guazuma ulmifolia, providing more vigorous seedlings.

Keywords: dormancy; germination behavior; establishment.

\section{INTRODUÇÃO}

Guazuma ulmifolia Lam. é uma espécie comum no Cerrado brasileiro, pertence à família Malvaceae e, popularmente, é conhecida como mutambo, mutamba, fruta-de-macaco, embira, embireira e mutamba-verdadeira (LORENZI e MATOS, 2002). Trata-se de uma espécie arbórea, semidecídua, com ampla distribuição geográfica, ocorrendo em toda América Latina (LORENZI, 1992). Segundo a classificação de Ferreti et al. (1995), essa espécie é considerada secundária inicial, pertencente a estágios iniciais de sucessão. Seu período de floração ocorre entre os meses de agosto e janeiro e os frutos imaturos podem ser encontrados de janeiro a setembro, com picos de ocorrência entre abril e junho (NUNES et al., 2005). Segundo esses autores, os frutos maduros apresentam maior concentração nos meses de agosto e novembro, com picos nos meses de setembro e outubro.

Os frutos de Guazuma ulmifolia são do tipo cápsulas subglobosa seca, pentacarpelares e polispérmicas, com sementes pequenas, medindo aproximadamente 3 a $5 \mathrm{~mm}$, com mucilagem que cobre o tegumento (CARVALHO, 2006). Estudos sobre a germinação das sementes de mutamba demonstraram presença de dormência tegumentar, indicando a necessidade de tratamentos prégerminativos para melhor eficiência da germinação dessa espécie (ARAÚJO NETO e AGUIAR, 2000; NUNES et al., 2006). Segundo Rolston (1978), a impermeabilidade do tegumento é um dos principais mecanismos de dormência em sementes de espécies tropicais e, segundo Cruz et al. (1997), pode atingir 98\% das sementes dessas espécies.

Os processos de escarificação, mecânicos ou químicos, constituem tratamentos pré-germinativos eficientes para a superação da dormência em sementes que apresentam o tegumento impermeável, propiciando alta porcentagem de germinação, em curto espaço de tempo (ESCHIAPATI-FERREIRA e PEREZ, 1997). A escarificação mecânica foi empregada com eficiência na superação da dormência de sementes de diversas espécies arbóreas, como Stryphnodendron pulcherrimum
(Willd.) Hochr. (VARELA et al., 1991), Bauhinia monandra Britt (ALVES et al., 2000) e Sesbania virgata (Cav.) Pers. (SILVA et al., 2011). Por outro lado, para as espécies Prosopis cineraria (L.) Druce, Acacia nilotica (L.) Willd ex Delile, Acacia tortilis (Forsk) Hayne (SACHETI e AL-RAWAHY, 1998) e Leucaena leucocephala (Lam.) de Wit (TELES et al., 2000), a escarificação térmica propiciou maior porcentagem de germinação das sementes.

Após a germinação, o estágio de plântula também sofre influência dos fatores ambientais. A disponibilidade de nutrientes, oxigênio, água, luz e temperatura, e também variáveis edáficas (características físicas e químicas e umidade do solo), assim, como as condições fisiológicas das sementes (qualidade e vigor) (ESCUDERO et al., 2000) determinam o crescimento diferencial de plântulas. A forma como uma espécie responde a esses fatores define o sucesso no estabelecimento de suas plântulas, que as tornam capazes de se desenvolver e atingir os próximos estádios do ciclo de vida (MELO et al., 2004). Por exemplo, o estabelecimento de uma espécie pode estar relacionado com a capacidade de suas sementes germinarem rápida e uniformemente, a fim de vencer a concorrência com outras espécies presentes no local (BORGES e RENA, 1993). Segundo Yap e Wong (1983), métodos de superação de dormência com altas temperaturas promovem fissuras no tegumento das sementes, facilitando a absorção de água e gases, desencadeando o processo germinativo e, consequentemente, o estabelecimento das plântulas. Do mesmo modo, a escarificação mecânica tem sido considerada um dos métodos mais eficientes no caso da impermeabilidade do tegumento à água (ALVES et al., 2000; OLIVEIRA et al., 2008).

Vários estudos demonstram o aumento no interesse quanto à propagação de espécies nativas, principalmente devido aos impactos antrópicos que, consequentemente, geram a necessidade de recuperação de áreas degradadas e recomposição da paisagem (ALVES et al., 2004). Apesar dos estudos sobre germinação de sementes serem importantes para o entendimento das estratégias reprodutivas das espécies e essenciais para subsidiar trabalhos 
de conservação e utilização de recursos genéticos, os aspectos que envolvem esse processo são, muitas vezes, pouco conhecidos para espécies nativas do Cerrado. Além disso, segundo Araújo Neto et al. (2003), as informações básicas sobre germinação, cultivo e potencialidades de espécies nativas podem ser utilizadas para diversos fins. As espécies de crescimento rápido, tais como a mutamba, podem ser utilizadas para auxiliar a regeneração de áreas impactadas e, desta forma, o conhecimento quanto ao desenvolvimento inicial desta espécie pode contribuir bastante para auxiliar programas que tenham tal finalidade.

Portanto, visando a um melhor conhecimento da ecologia de Guazuma ulmifolia, este trabalho teve como objetivo determinar uma metodologia simples e eficiente para acelerar e aumentar o desempenho germinativo (porcentagem de sementes germinadas e índice de velocidade de germinação) e promover o estabelecimento desta espécie visando à produção de mudas.

\section{MATERIAIS E MÉTODOS}

\section{Local e coleta de propágulos}

A coleta dos frutos foi realizada em 10 matrizes de Guazuma ulmifolia, inseridas na Área de Proteção Ambiental (APA) do Rio Pandeiros, em outubro de 2008. Especificamente, as matrizes localizavam-se próximo ao Refúgio de Vida Silvestre do Rio Pandeiros $\left(44^{\circ} 4512^{\prime}\right.$ S e $44^{\circ} 45^{\prime} 12^{\prime}$ W), inserido no município de Januária, no norte de Minas Gerais. A região é caracterizada pela transição entre os domínios de Cerrado e Caatinga, com fitofisionomias bem diferenciadas (NUNES et al., 2009). O clima, de acordo com a classificação de Köppen, é tropical chuvoso e seco (Aw), com estações secas e chuvosas bem definidas e a precipitação média anual varia entre 900 a $1200 \mathrm{~mm}$, com chuvas concentradas nos meses de novembro a janeiro e a temperatura média varia de $21^{\circ}$ a $24^{\circ} \mathrm{C} /$ ano (MENINO et al., 2012). Os tipos de solo encontrados na APA do Rio Pandeiros são Neossolos, com boa permeabilidade, Cambissolos, de textura arenosa com baixa fertilidade natural e Gleissolos típicos de terrenos inundáveis (NUNES et al., 2009).

As árvores-matrizes distavam-se, pelo menos, $50 \mathrm{~m}$ entre si. De cada árvore, foram retirados 50 frutos maduros, totalizando 500 frutos, que foram armazenados em sacos de papel. Após a coleta, os frutos foram transportados para o Laboratório de Ecologia Vegetal da Universidade Estadual de Montes Claros (UNIMONTES), onde foram abertos manualmente para extração das sementes, sendo as sementes separadas em lote homogêneo (com número de sementes semelhante entre matrizes), conforme cor e tamanho, sendo eliminadas aquelas que apresentaram aspecto diferente do normal da espécie e atacadas por patógenos. Após a coleta, as sementes permaneceram cinco meses armazenadas, período em que foram realizados outros estudos referentes à biometria de frutos (não integrante deste trabalho). Apesar disto, as sementes de mutamba, após um ano de coleta, apresentam viabilidade germinativa semelhante às sementes recém-colhidas (ARAÚJO NETO e AGUIAR, 2000).

\section{Condução dos experimentos}

Para determinar o efeito dos tratamentos prégerminativos na emergência e no estabelecimento de plântulas, foram selecionadas, no total, 900 sementes de Guazuma ulmifolia, sendo utilizadas 300 sementes em cada tratamento. As sementes foram submetidas aos seguintes tratamentos prégerminativos (NUNES et al., 2006): (1) escarificação mecânica, em que uma das extremidades das sementes (ao lado oposto a micrópila) foi lixada (lixa de parede $\mathrm{n}^{\circ} 80$ ) até a retirada do tegumento; e (2) escarificação térmica, com a imersão das sementes em água quente a $70^{\circ} \mathrm{C}$, permanecendo imersas até que a temperatura da água atingisse $50^{\circ} \mathrm{C}$ (em torno de $30 \mathrm{~min}$ ). Além disso, foi mantido um tratamentocontrole (3), cujas sementes permaneceram intactas. Após a aplicação dos tratamentos, as sementes foram semeadas a $1 \mathrm{~cm}$ de profundidade, em sacos plásticos pretos de polietileno, nas dimensões $35 \mathrm{~cm} \times 20 \mathrm{~cm}(3 \mathrm{Kg})$, contendo uma mistura de terra e areia, na proporção de $3: 1$, respectivamente. Foi utilizado um delineamento experimental inteiramente casualizado (DIC), com três tratamentos e nove repetições de 10 sacos plásticos, com uma semente em cada, totalizando 27 amostras. $\mathrm{O}$ experimento foi conduzido em casa de vegetação com teto de plástico, para controle da umidade, e laterais de sombrite, localizada na Área Experimental da Biologia, da UNIMONTES. Para a análise da emergência de plântulas, o experimento foi observado diariamente no mesmo horário, durante 30 dias, entre os meses de março e abril de 2009, utilizando como critério de emergência a presença de cotilédones abertos e aparecimento da parte 
aérea acima da superfície do solo (BARRADAS e HANDRO, 1974). Para a análise de estabelecimento, foram utilizadas todas as plântulas que adquiriam altura mínima de $2 \mathrm{~cm}$, no período de abril a junho de 2009 , totalizando quatro observações com intervalo de 15 dias. Deste modo, foram tomadas as medidas de DAS (diâmetro a altura do solo), com o uso de um paquímetro digital (DIGIMESS ${ }^{\circledR}$ ), com precisão de $0,01 \mathrm{~mm}$, e de altura total (do colo até a última gema apical do ramo principal), com o auxílio de régua milimetrada; e contado o número de folhas e de nós de cada plântula (PAIVA e POGGIANI, 2000). A duração total do experimento foi de 90 dias, sendo os 30 dias iniciais utilizados para a observação da emergência das plântulas e os 60 dias restantes para a observação do crescimento e estabelecimento das plântulas.

\section{Análise dos dados}

No experimento de emergência foram calculados a porcentagem de germinação $(\mathrm{G} \%)$ e o índice de velocidade de germinação (IVG) (BORGHETTI e FERREIRA, 2004). A porcentagem de germinação foi determinada pela formula: $\% \mathrm{G}$ $=\mathrm{Gn} / \mathrm{Nn} * 100$, na qual $\mathrm{Gn}$ corresponde ao número total de plântulas germinadas, em cada unidade amostral, durante o período de avaliação e $\mathrm{Nn}$, o número total de sementes colocadas para germinar (BORGHETTI e FERREIRA, 2004). O IVG, que mede a velocidade de germinação, foi determinado, pelo somatório do número de plântulas emergidas a cada dia, dividido pelo número de dias decorridos entre a montagem do experimento e a emergência da plântula, de acordo a fórmula descrita por Maguire (1962), em que: IVG: G1/N1 + G2/N2 $+\mathrm{G} 3 / \mathrm{N} 3+\mathrm{G} 4 / \mathrm{N} 4+\ldots .+\mathrm{Gn} / \mathrm{Nn}$, onde, G1, G2, $\mathrm{G} 3, \ldots, \mathrm{Gn}$ é o número de sementes germinadas em cada contagem, na primeira, segunda, terceira, ... e na enésima contagens; e N1, N2, N3, ...., Nn são o número de dias, dia 1 , dia 2 , dia $3, \ldots$ e enésimo dia, após a montagem do experimento. Para a análise do estabelecimento das plântulas, foram utilizadas as médias dos valores de crescimento das diferentes variáveis analisadas (altura, diâmetro e número de folhas e de nós). Para isto, foram tomados os valores finais, subtraídos dos iniciais, de cada plântula, e retirada, posteriormente, a média de crescimento de cada repetição.

Para detectar diferenças quanto à porcentagem e à velocidade de germinação, bem como o estabelecimento das plântulas entre os tratamentos pré-germinativos foi realizada a Análise de Variância - ANOVA e o teste de Tukey, a 5\% de probabilidade (ZAR, 1996). As análises foram realizadas no software estatístico STATISTICA versão 10 (HILL e LEWICKI, 2007; STATISTICA, 2011). Anteriormente ao teste, para homogeneização das variâncias, os valores percentuais foram transformados para arcsen da raiz da porcentagem de germinação (SANTANA e RANAL, 2004), mas nas tabelas e figuras são apresentadas as médias dos dados originais. Para as análises estatísticas foi realizado o teste de normalidade Kolmogorov-Smirnov (ZAR, 1996), para verificação da normalidade dos dados.

\section{RESULTADOS E DISCUSSÃO}

A emergência das plântulas de Guazuma ulmifolia foi influenciada pelos tratamentos prégerminativos $(\mathrm{gl}=2 ; \mathrm{F}=6,22 ; \mathrm{n}=90 ; \mathrm{p}<0,01)$. A maior porcentagem de emergência $(70,00 \pm 4,58 \%)$ foi encontrada no tratamento de escarificação térmica, enquanto que, a menor porcentagem $(47,03 \pm 3,75 \%)$ foi observada no tratamento de escarificação mecânica (Figura 1).

Entretanto, a porcentagem de emergência de plântulas provenientes de sementes lixadas não diferiu daquela das sementes intactas $(\mathrm{p}>0,05)$, sendo ambas estatisticamente menores que as sementes submetidas à imersão em água quente, segundo o teste de Tukey. Apesar disto, não foi observada diferença estatística entre os tratamentos para o IVG das sementes $(\mathrm{gl}=2 ; \mathrm{F}=0,143 ; \mathrm{n}=90$; $\mathrm{p}=0,867)$ (Figura 2).

Diferentes causas de dormência podem ser atribuídas à semente, como impermeabilidade do tegumento à água e às trocas gasosas, resistência mecânica do tegumento ao crescimento do embrião, presença de inibidores da germinação e imaturidade fisiológica (BASKIN e BASKIN, 1998). Em algumas espécies, as temperaturas altas podem funcionar como um mecanismo de quebra de dormência (ZAIDAN e BARBEDO, 2004). Segundo Gray (1962), a água quente atua sobre o tegumento fazendo com que surja uma série de microfraturas ao longo da testa da semente, favorecendo a embebição e posterior geminação. Várias espécies demonstram superar a dormência quando suas sementes são imersas em água quente. Assim, provavelmente, a alta temperatura pode ter sido determinante na quebra de dormência tegumentar das sementes de 


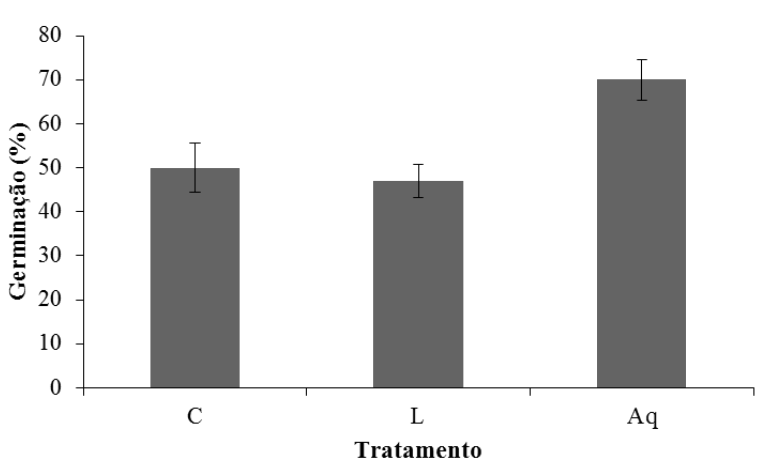

FIGURA 1: Porcentagem de emergência de plântulas de Guazuma ulmifolia Lam. provenientes de sementes submetidas a diferentes tratamentos pré-germinativos $(\mathrm{C}-$ Controle, $\mathrm{L}$ - Lixa e Aq - Água quente). Médias seguidas da mesma letra não diferem estatisticamente ( $5 \%$ de probabilidade) pelo teste de Tukey.

FIGURE 1: Percentage of emergence of Guazuma ulmifolia Lam. seedlings, from seeds submitted to different pre-germination treatments (C- Control, L- sandpaper and Aq- hot water). Means followed by the same letter do not differ statistically ( $5 \%$ probability) by Tukey test.

Guazuma ulmifolia, como já observado em outros estudos (LIMA et al., 2003; NUNES et al., 2006). Para Mimosa bimucronata (DC.) O. Kuntze, a quebra de dormência ocorre quando suas sementes são imersas em água a $80^{\circ} \mathrm{C}$, seguido de esfriamento na mesma água por 24 horas (RIBAS et al., 1996) e em Acacia senegal (L.) Willd. e Parkinsonia aculeata L., entre $80-90^{\circ} \mathrm{C}$ (TORRES e SANTOS, 1994). Sementes de Ochroma pyramidale (Cav. ex Lam.) Urb., espécie pertencente à mesma família da Guazuma ulmifolia (Malvaceae), também apresentaram resultados satisfatórios de germinação quando imersas em água quente. Para as sementes desta espécie, houve germinação de mais de $60 \%$ quando imersas em água fervente por 4 minutos, no trabalho desenvolvido por Netto (1994), e de $89 \%$ a $80^{\circ} \mathrm{C}$, no estudo de Varela e Ferraz (1991), quando tratadas com água quente por cerca de $20 \mathrm{~min}$. Alguns autores, como Wang (1975) e Candido et al. (1982), ressaltam a vantagem do tratamento de escarificação térmica por ser simples e econômico, não requerendo equipamentos especiais, além de poder

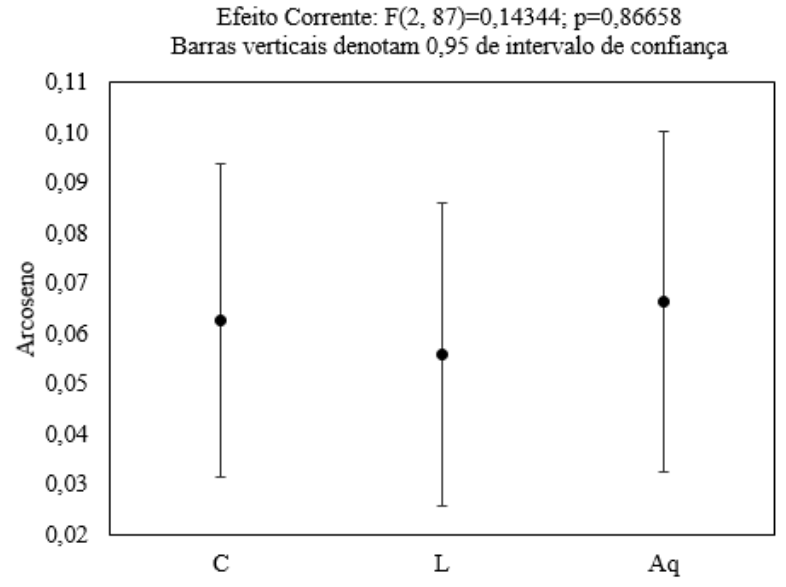

FIGURA 2: Índice de velocidade de germinação das sementes de Guazuma ulmifolia Lam. submetidas a diferentes tratamentos pré-germinativos ( $\mathrm{C}$ - Controle, $\mathrm{L}$ Lixa e Aq - Água quente).

FIGURE 2: Germination speed index of Guazuma ulmifolia Lam. seeds submitted to different pre-germination treatments (C- Control, L- sandpaper and Aq- hot water).

ser usado para qualquer quantidade de sementes. No entanto, trabalhos como o de Varela et al. (1991), com Stryphnodendron pulcherrimum (Willd.) Hochr, e de Costa et al. (2010), com Adenanthera pavonina $\mathrm{L}$, obtiveram resultados negativos com a utilização da escarificação térmica, visto que esse tratamento danificou as sementes testadas. Varela et al. (1991) ainda enfatizam que tal método não pode ser empregado indiscriminadamente para sementes de qualquer espécie. Entretanto, experimentos que testem diferentes tempos de exposição a diferentes temperaturas ou variações abruptas entre temperaturas mais quentes e frias podem descrever melhor o comportamento germinativo da mutamba em relação à escarificação térmica.

Diferentemente da escarificação térmica, a escarificação mecânica não se mostrou um método eficiente para quebra de dormência das sementes de mutamba. Houve um baixo número de plântulas emergidas $(14,6 \pm 1,85 \%$ ), assim como o menor valor do índice de velocidade de germinação $(5,58$ $\pm 0,13$ ), entre os tratamentos (Tabela 1).

Esse fato pode estar relacionado à alta resistência mecânica do tegumento encontrado nas sementes dessa espécie. Portanto, a ação abrasiva no tegumento pode não ter sido capaz 
TABELA 1: Comportamento germinativo das sementes de Guazuma ulmifolia Lam. em função de diferentes tratamentos pré-germinativos. Médias seguidas da mesma letra não diferem estatisticamente ( $5 \%$ de probabilidade) pelo teste de Tukey.

TABLE 1: Germination behaviour of Guazuma ulmifolia Lam. seeds submitted to different pre-germination treatments. Means followed by the same letter do not differ statistically (5\% probability) by Tukey test.

\begin{tabular}{cccccc}
\hline Tratamentos & $\begin{array}{c}\text { Porcentagem } \\
\text { emergência } \\
(\overline{\mathrm{X}} \pm \mathrm{DP})\end{array}$ & $\begin{array}{c}\text { Plântulas } \\
\text { germinadas } \\
(\overline{\mathrm{X}} \pm \mathrm{DP})\end{array}$ & $\begin{array}{c}\text { IVG } \\
(\overline{\mathrm{X}} \pm \mathrm{DP})\end{array}$ & $\begin{array}{c}\text { Pico de } \\
\text { emergência } \\
(\text { dia })\end{array}$ & $\begin{array}{c}\text { Duração da } \\
\text { Germinação } \\
\text { (dias) }\end{array}$ \\
\hline Controle & $50,00 \pm 30,03 \mathrm{a}$ & $15,00 \pm 2,78$ & $8,53 \pm 0,139$ & $13^{\circ}$ & $9-23$ \\
Lixa & $47,00 \pm 20,56 \mathrm{a}$ & $14,60 \pm 1,85$ & $5,58 \pm 0,134$ & $15^{\circ}$ & $9-25$ \\
Água Quente & $70,00 \pm 25,16 \mathrm{~b}$ & $21,20 \pm 2,26$ & $6,64 \pm 0,015$ & $13^{\circ}$ & $7-26$ \\
\hline
\end{tabular}

de causar fissuras suficientes para que houvesse a embebição das sementes e reativação do processo de germinação. Assim, estes resultados mostraram que a emergência de plântulas provenientes de sementes submetidas à escarificação mecânica foi semelhante àquela ocorrida nas sementes intactas (tratamento-controle), não apresentando diferença estatística entre estes tratamentos. Entretanto, na literatura, várias espécies demonstraram sucesso quando o método de escarificação mecânica foi empregado para a superação da dormência de sementes, como: Bauhinia ungulata (ALVES et al., 2000), Dimorphandra mollis Benth. (OLIVEIRA et al., 2008) e Peltophorum dubium (Spreng.) Taub. (PIROLI et al., 2005). A dureza do tegumento associado ao tamanho da semente (2 a $3 \mathrm{~mm}$ ) pode ter sido a causa da ineficácia do tratamento com lixa, tornando esse método impróprio para a quebra de dormência tegumentar das sementes dessa espécie.

Observou-se também que as sementes de todos os tratamentos apresentaram maiores porcentagens de emergência entre o décimo terceiro e o décimo quinto dia de incubação. Segundo Vazquez-Yanes e Orozco-Segovia (1993), espécies pioneiras, com típica característica de produção de grande quantidade de sementes de tamanho pequeno, são associadas com a estratégia de atraso na germinação. Essa estratégia maximiza as chances de colonizar clareiras ou de serem incorporadas ao banco de sementes até que as condições ótimas de luz iniciem o processo de germinação. Em ambientes naturais, a germinação de sementes e emergência das plântulas em intervalos irregulares aumenta a probabilidade de alguns indivíduos sobreviverem (FOWLER e BIANCHETI, 2000). Além disso, estes mesmos autores mencionam que a distribuição da germinação ao longo do tempo favorece a germinação das sementes somente após a superação de fatores ambientais adversos. No presente estudo, os resultados demonstraram que as sementes de Guazuma ulmifolia apresentam dormência tegumentar, no entanto, os tratamentos para quebra de dormência não influenciaram no tempo de emergência ou velocidade da germinação. Isso mostra que, apesar de altas temperaturas favorecerem a emergência, a escarificação não interfere no tempo, não havendo diferença significativa de IVG entre os tratamentos (Figura 2).

Foi observada mixospermia nessa espécie, ou seja, presença de mucilagem nas sementes quando em contato com água. Segundo Carmona et al. (1994), a presença de mucilagem aderida às sementes pode prejudicar a germinação e o desenvolvimento das plântulas. A mucilagem favorece o desenvolvimento de microrganismos e pode conter substâncias inibidoras de germinação (CARMONA et al., 1994). Contudo, apesar de este estudo não avaliar o efeito da mucilagem sobre a emergência de plântulas, pode-se dizer que a mucilagem encontrada nas sementes de Guazuma ulmifolia tratadas com a água quente não interferiu na emergência, já que foram observadas altas porcentagens de emergência nesse tratamento. Melchior et al. (2006), trabalhando com sementes 
de Campomanesia adamantium Camb., observaram taxas de germinação acima de $80 \%$, mesmo com a presença de mucilagem aderida às sementes. Os autores sugerem que a mucilagem não apresenta substâncias inibidoras da germinação, contestando assim, a necessidade de retirá-la da semente.

Dentro do ciclo de vida das plantas com sementes, o recrutamento, o desenvolvimento e a sobrevivência das plântulas são eventos cruciais para o crescimento e manutenção das populações (MELO et al., 2004). Desse modo, foi observada diferença significativa no crescimento em altura $(\mathrm{gl}=2 ; \mathrm{F}=19,03 ; \mathrm{n}=90 ; \mathrm{p}<0,001)$, diâmetro $(\mathrm{gl}=2 ; \mathrm{F}=16,48 ; \mathrm{n}=90 ; \mathrm{p}<0,001)$, número de folhas $(\mathrm{gl}=2 ; \mathrm{F}=12,47 ; \mathrm{n}=90 ; \mathrm{p}<0,001)$ e número de nós $(\mathrm{gl}=2 ; \mathrm{F}=11,47 ; \mathrm{n}=90 ; \mathrm{p}<0,001)$ no estabelecimento das plântulas, conforme os tratamentos pré-germinativos (Figura 3).

Estes resultados mostraram que $\mathrm{o}$ desenvolvimento das plântulas de Guazuma ulmifolia sofreu interferência dos tratamentos feitos às sementes, principalmente da escarificação térmica, que propiciou plântulas mais vigorosas. Assim, plântulas provenientes de sementes tratadas com água quente obtiveram maior crescimento em altura, DAS e um maior incremento de folhas e de nós, sendo observada através do teste de Tukey diferença significativa entre esse tratamento e os demais $(p<0,01)$. Já os tratamentos de lixa e controle não diferiram estatisticamente $(\mathrm{p}>0,05)$. Segundo Baskin e Baskin (1998), o aumento da temperatura resulta em altas taxas de respiração na maioria das sementes, diminuindo o tempo de dormência e quiescência. Assim, processos fisiológicos intrínsecos das sementes podem ser reativados, ocasionando uma germinação mais rápida, o que pode favorecer o maior desenvolvimento das plântulas (YAP e WONG, 1983).
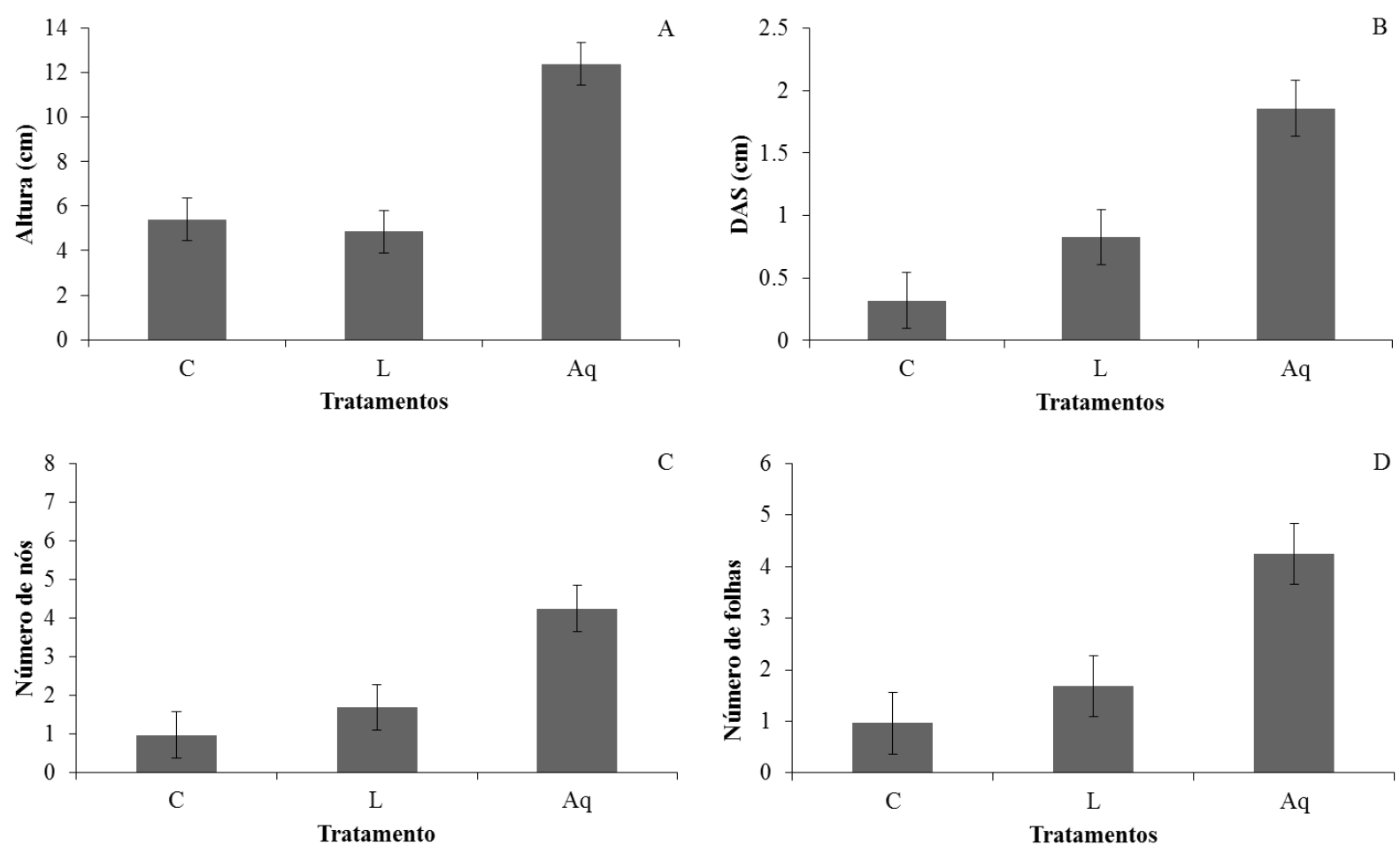

FIGURA 3: Desenvolvimento de plântulas de Guazuma ulmifolia Lam. após tratamentos pré-germinativos (C - Controle, L - Lixa e Aq - Água quente) aplicados em suas sementes. (A) Altura, (B) DAS (diâmetro a altura do solo), (C) número de nós e (D) de folhas as plântulas, após 60 dias de avaliação. Médias seguidas da mesma letra não diferem estatisticamente ( $5 \%$ de probabilidade) pelo teste de Tukey.

FIGURE 3: Development of Guazuma ulmifolia Lam. seedlings after pre-germination treatments (CControl, L- sandpaper e Aq- hot water) applied in their seeds. (A) Height. (B) DAS (diameter at soil level), (C) number of leaves and (D) number of nodes, after 60 days of evaluation. Means followed by the same letter do not differ statistically (5\% probability) by Tukey test. 
Segundo Larcher (2000), o sucesso no estabelecimento de plântulas está diretamente relacionado com a alta qualidade da estrutura germinativa. Assim, a germinação e o estádio de plântula representam um período sensível no ciclo de vida. Para Harper (1977), a forma e o tamanho das sementes, assim como o tipo de quebra de dormência, influenciam o desenvolvimento das plântulas, o que pode ser observado no presente estudo, já que houve maior desenvolvimento das plântulas em sementes escarificadas em água quente. Grus (1990) afirma que, para espécies com tegumentos resistentes e impermeáveis à água, qualquer procedimento (e.g. escarificação) que permita romper o tegumento das sementes, fazendo-as absorver água, promove sua germinação e a emergência de plântulas geralmente vigorosas. Dessa forma, a temperatura promove a quebra da dormência nas sementes de Guazuma ulmifolia, o que também pode favorecer a absorção de água e assim garante um melhor desenvolvimento e crescimento das plântulas advindas das sementes escarificadas termicamente. Segundo Lorenzi e Matos (2002), espécies de estádios iniciais de sucessão, como Guazuma ulmifolia, desenvolvem-se em ambientes abertos e com alta disponibilidade de luz. Dessa forma, o maior investimento em crescimento observado nesse estudo é uma estratégia ecológica que garante à espécie o estabelecimento no ambiente, já que se observa grande competição por espaço e recursos em estágios iniciais de sucessão.

Lima e Garcia (1996) obtiveram plântulas de Acacia mangium Wild. com maior comprimento quando as sementes foram submetidas ao tratamento de imersão em água à temperatura de $80^{\circ} \mathrm{C}$ até atingir a temperatura ambiente (em torno de 2 horas). Também no trabalho de Melo e Rodolfo Júnior (2006), com Cassia grandis L.f., a imersão em ácido e em água quente por 12 horas determinaram maiores valores para crescimento em altura, número de folhas e comprimento da raiz principal de plântulas. Estes resultados reforçam a eficiência do tratamento da escarificação térmica, não apenas para aumentar a performance germinativa mas para auxiliar no crescimento e estabelecimento de plântulas de diversas espécies.

\section{CONCLUSÃO}

Observou-se dormência tegumentar em sementes de Guazuma ulmifolia, na qual as sementes escarificadas termicamente $\left(70^{\circ} \mathrm{C}\right)$ apresentam maior porcentagem de emergência e plântulas mais vigorosas, com maior crescimento em altura, diâmetro e número de folhas e nós. Assim, tratamentos pré-germinativos, que utilizam temperatura, são indicados para a produção de mudas desta espécie.

\section{AGRADECIMENTOS}

Este estudo integrou o projeto "Fitoindicadores ecológicos para recuperação de matas ciliares na região do médio São Francisco, Minas Gerais", financiado pelo CNPq (processo 555980/2006-5). Os autores agradecem a Petrobrás, pela bolsa de mestrado da primeira autora; ao CNPq pela bolsa de pesquisa de Y.R.F. Nunes e G.W. Fernandes; à FAPEMIG pela bolsa de BIPDT de M.D.M. Veloso; ao IEF-MG e a UNIMONTES pelo apoio logístico; e aos estagiários do Laboratório de Ecologia Vegetal da UNIMONTES pelo auxílio.

\section{REFERÊNCIAS BIBLIOGRÁFICAS}

ALVES, M. C. S. et al. Superação da dormência de sementes de Bauhinia monandra Britt. e Bauhinia ungulata L. - Caesalpinoideae. Revista Brasileira de Sementes, Brasília, v. 22, n. 2, p. 139-144, 2000. ALVES, A. U. et al. Superação da dormência em sementes de Bauhinia divaricata L. Acta Botanica Brasilica, Brasília, v. 18, n. 4, p. 871-879, 2004. ARAÚJO NETO, J. C.; AGUIAR, I. B. Germinative pretreatmenst to dormancy break in Guazuma ulmifolia Lam. seeds. Scientia Forestalis, Piracicaba, n. 58, p. 15-24, 2000.

ARAÚJO NETO, J. C.; AGUIAR, I. B.; FERREIRA, V. M. Efeito da temperatura e da luz na germinação de sementes de Acacia polyphylla DC. Revista Brasileira de Botânica, São Paulo, v. 26, n. 2, p. 249-256, 2003.

BARRADAS, M. M.; HANDRO, W. Some observations on seed germination in "barbatimão" Stryphnodendron barbadetimam (Vell) Mart. (Leguminosae-Mimosoideae). Boletim de Botânica, São Paulo, v. 2, p. 139-150, 1974.

BASKIN, C. C.; BASKIN, J. M. Seeds: ecology, biogeography, and evolution of dormancy and germination. San Diego: Academic Press, 1998. $666 \mathrm{p}$.

BORGES, E. E. L.; RENA, A.B. Germinação de sementes. In: AGUIAR, I. B.; PIÑA-RODRIGUES, F. C. M.; FIGlioliA, M. B. (Ed.). Sementes florestais tropicais. Brasília: ABRATES, 1993. 
p. 83-135.

BORGHETTI, F.; FERREIRA, A.G. Interpretação de resultados de germinação. In: FERREIRA, A.G.; BORGHETTI, F. (Org.). Germinação: do básico ao aplicado. Porto Alegre: ARTMED, 2004. p. 209-222.

CARMONA, R.; REZENDE, L. P.; PARENTE, T. V. Extração química de sementes de gabiroba (Campomanesia adamantium Camb.). Revista Brasileira de Sementes, Brasília, v. 16, n. 1, p. 31-33, 1994.

CARVALHO, P. E. R. Espécies arbóreas brasileiras. v.2. Brasília: Emprapa Informação Tecnológica. $627 \mathrm{p}$.

COSTA, P. A. et al. Quebra de dormência em sementes de Adenanthera pavonina L. Pesquisa Agropecuária Tropical, Goiânia, v. 40, n. 1, p. 83-88, 2010.

CRUZ, E. D.; CARVALHO, J. E. U.; OLIVEIRA, R. P. Variabilidade na germinação e dormência em sementes de Centrosema pubescens Benth. Pasturas Tropicales, Cali, v. 19, p. 37-41, 1997. ESCUDERO, A.; NÚNEZ, Y.; PÉREZ-GARCÍA, F. Is fire a selective force of seed size in pine species? Acta Oecologica, Berlin, v. 21, p. 245-256, 2000. ESCHIAPATI-FERREIRA, M. S.; PEREZ, S. C. J. G. A. Tratamentos para superar a dormência de sementes de Senna macranthera. Revista Brasileira de Sementes, Brasília, v. 19, n. 2, p. 231-237. 1997. FOWLER, A. J. P.; BIANCHETTI, A. Dormência em sementes florestais. Brasília, Colombo: Embrapa Florestas. (Documentos 40), 2000. 27 p. GRUS, V. M. Germinação de sementes de pauferro e Cassia javanesa submetidas a tratamentos para quebra de dormência. Revista Brasileira de Sementes, Brasília, v. 2, n. 6, p. 29-35, 1990.

GRAY, S. G. Hot water seed treatment for Leucaena glauca (L.) Benth. Australian. Journal of Experimental Agriculture and Animal Husbrandry, Melbourne, v. 2, p. 178-180, 1962.

HARPER, J. L.Population biology of plants. London: Academic Press, 1977. 892 p.

HILL, T.; LEWICKI, P. STATISTICS: methods and applications. Tulsa: StatSoft, 2007. 832 p.

LARCHER, W. Ecofisiologia vegetal. São Carlos, RiMa, 2000. 531 p.

LIMA, D.; GARCIA, L. C. Avaliação de métodos para o teste de germinação em sementes de Acacia mangium Willd. Revista Brasileira de Sementes, Lavras, v. 18, n. 2, p. 180-185, 1996.

LIMA, A. A. A.; MEDEIROS FILHO, S.; TEÓFILO, E. M. Germinação de sementes de turco (Parkinsonia aculeata L.) e mutamba (Guazuma ulmifolia Lam.) em diferentes ambientes e submetidas a metodologias para superação da dormência. Revista Científica Rural, Brasília, v. 8, n. 1, p. 46-54, 2003.

LORENZI, H. Árvores brasileiras: manual de identificação e cultivo de plantas arbóreas nativas do Brasil. Nova Odessa: Instituto Plantarum, 1992. $382 \mathrm{p}$.

LORENZI, H.; MATOS, F. J. A. Plantas medicinais no Brasil: nativas e exóticas cultivadas. Nova Odessa: Instituto Plantarum, 2002. 512 p.

MAGUIRE, J. D. Speed of germination-aid in selection and evaluation for seedling emergence and vigor. Crop Science, Madison, v. 2, n. 1, p. 176-177, 1962.

MELO, P. L. et al. Recrutamento e estabelecimento de plântulas. In: FERREIRA, A.G.; BORGHETTI, F. (Org.). Germinação: do básico ao aplicado. Porto Alegre: ARTMED, 2004. p. 238-250. 323p.

MELO, R. R.; RODOLFO JÚNIOR, F. Superação de dormência em sementes de canafístula (Cassia grandis L.f.). Revista Científica Eletrônica de Engenharia Florestal, v. 6, n. 7, 2006.

MENINO, G. C. O. et al. Environmental heterogeneity and natural regeneration in riparian vegetation of the Brazilian semi-arid region. Edinburgh Journal of Botany, Edinburgh, v. 69, n. 1, p. 29-51, 2012.

MELCHIOR, S. J. et al. Colheita e armazenamento de sementes de gabiroba (Campomanesia adamantium Camb. - Myrtaceae) e implicações na germinação. Revista Brasileira de Sementes, Pelotas, v. 28, n. 3, p. 141-150, 2006.

NUNES, Y. R. F. et al. Germinação de sementes de Guazumaulmifolia Lam.(Malvaceae)e Heteropterys byrsonimifolia A. Juss (Malpighiaceae) sob diferentes tratamentos de escarificação tegumentar. Unimontes Científica, Montes Claros, v. 8, n. 1. p. 43-52, 2006.

NUNES, Y. R. F. et al. Atividades fenológicas de Guazuma ulmifolia Lam. (Malvaceae) em uma Floresta Estacional Decidual no norte de Minas Gerais. Lundiana, Belo Horizonte, v. 6, p. 99-105, 2005.

NUNES, Y. R. F. et al. Pandeiros: o pantanal mineiro. MG BIOTA, Belo Horizonte, v. 2, n. 2, p. 4-17, 2009.

MARTINS NETTO, D. A. Germinação de sementes de pau-de-balsa (Ochroma pyramidale Cav. ex Lam. Urban., Bombacaceae). Revista Brasileira de Sementes, Lavras, v. 16, n. 2, p. 159-162, 1994. 
OLIVEIRA, D. A. et al. Potencial germinativo de sementes de fava-d'anta (Dimorphandra mollis Benth. - Fabaceae: Mimosoideae) sob diferentes procedências, datas de coleta e tratamentos de escarificação. Revista Árvore, Viçosa, v. 32, n. 6, p. 1001-1009, 2008.

PAIVA, A. V.; POGGIANI, F. Crescimento de mudas de espécies arbóreas nativas plantadas no sub-bosque de um fragmento florestal. Scientia Forestalis, Piracicaba, v. 57, n. 3, p. 141-151, 2000. PIROLI, E. L. et al. Germinação de sementes de canifístula Peltophorum dubium (Spreng) Taub. Tratadas para superação da dormência. Colloquium Agrariae, São Paulo, v. 1, n. 1, p. 13-18, 2005.

RIBAS, L. L. F.; FOSSATI, L. C.; NOGUEIRA, A. C. Superação da dormência de sementes de Mimosa bimucronata (DC.) O. Kuntze (maricá). Revista Brasileira de Sementes, Brasília, v. 18, n. 1, p. 98-101, 1996.

SANTANA, D. G.; RANAL, M. A. Análise da germinação: um enfoque estatístico. Brasília: Editora UnB, 2004. 247 p.

ROLSTON, M. P. Water impermeable seed dormancy. Botanical Review, Lancaster, v. 44, p. 365-396, 1978.

SACHETI, U.; AL-RAWAHY, S. H. The effects of various pretreatments on the germination of important leguminous shrub-tree species of the Sultanate of Oman. Seed Science and Technology, Zurich, v. 26, n. 3, p. 691-699, 1998.

SILVA, P. E. M. et al. Quebra de dormência em sementes de Sesbania virgata (Cav) Pers. IDESIA, Arica, v. 29, n. 2, p. 39-45, 2011.

STATISTICA (data analysis software system),
STATSOFT, Inc. version 10. www.Statsoft.com, 2011.

TELES, M. M. et al. Métodos para quebra da dormência em sementes de leucena (Leucaena leucephala (Lam.) de Wit). Revista Brasileira de Zootecnia, Viçosa, v. 29, n. 2, p. 387-391, 2000.

TORRES, S. B.; SANTOS, S. S. B. Superação da dormência em sementes de Acacia senegal (L.) Willd. e Parkinsonia aculeata L. Revista Brasileira de Sementes, Brasília, v. 16, n. 1, p. 54-57, 1994. WANG, B. S. P. Metodologia de la conservacion de los recursos geneticos forestales. Roma: Food and Agriculture Organization, p. 93-103, 1975.

ZAIDAN, L. B. P.; BARBEDO, C. J. Quebra de dormência em sementes. In: FERREIRA, A. G.; BORGHETTI, F. (Org.) Germinação: do básico ao aplicado. São Paulo: Artmed, 2004. p. 135-146.

VARELA, V. P.; FERRAZ, I. D. K. Germinação de sementes de pau de balsa. Pesquisa Agropecuária Brasileira, Brasília, v. 26, n. 10. p. 1685-1689, 1991.

VAZQUEZ-YANES, C. V.; OROZCO-SEGOVIA, A. 1993. Patterns of seed longevity and germination in the tropical rainforest. Annual Review of Ecology and Systematics, Palo Alto, v. 24, p. 69-87.1993.

YAP, S. K.; WONG, S. M. Seed biology of Acacia mangium, Albizia falcataria, Eucalyptus sp., Gmelina arborea, Malsopsis eminiis, Pinus caribaea and Tectonia grandis. The Malaysian Forester, Kuala Lumpur, v. 6, n. 1, p. 16-45, 1983. ZAR, J.H. Biostatistical analysis. 3rd. ed. New Jersey: Prentice Hall, 1996. 662p 